\section{REFLEXÕES ACERCA DO ACESSO À APOSENTADORIA EM FACE DO GÊNERO}

\section{REFLECTIONS ON ACCESS TO RETIREMENT IN THE FACE OF GENDER}

Fabiana Larissa Kamada ${ }^{1}$

Rosa Costa Cantal ${ }^{2}$

\title{
RESUMO
}

Este artigo científico tem como objetivo promover uma reflexão a respeito das alterações promovidas pela Emenda Constitucional nº 103/2019 com relação aos requisitos necessários para aposentadoria da mulher em comparação com a aposentadoria do homem. Apresenta uma análise sobre a participação de homens e mulheres no mercado de trabalho (remunerado), bem como as horas dedicadas à reprodução social, que não são contabilizadas para fins de aposentadoria, a partir da demonstração das inter-relações entre as suas atividades laborais e sociais. O presente trabalho examinou estudos que mostraram a dificuldade enfrentada pela mulher para conseguir o tempo necessário para aposentadoria, uma vez que manter-se no emprego, por inúmeros fatores, é muito mais complicado para ela. Dessa forma, verificar-se-á se houve mudanças significativas no mercado de trabalho da mulher, bem como se há uma igualdade de condições entre os sexos de modo a justificar essas alterações, uma vez que os requisitos ficaram ainda mais rigorosos para as mulheres e que isso pode impactar de forma negativa para elas.

Palavras-chaves: Aposentadoria da mulher. Covid-19. Desigualdade de gênero. Mercado de trabalho. Reprodução social.

\footnotetext{
1 Doutoranda em Função Social no Direito Constitucional pela Faculdade Autônoma de Direito - Fadisp. Mestre em Direito Político e Econômico pela Universidade Presbiterana Mackenzie. Especialista em Direito e Processo do Trabalho. E-mail: fabianakamada@yahoo.com.br. ORCID iD 0000-0001-91424754.

2 Bacharel em Direito pela Universidade Presbiteriana Mackenzie (2005). Possui Pós-graduação em Processo Civil pela Faculdade Autônoma de Direito (Fadisp-2009). Advogada responsável pelo Núcleo Jurídico de Defesa e Convivência da Mulher e Centro de Integração Social da Mulher (Cism II), da Associação Fala Mulher (2008-2010). É mestranda em Direito Constitucional pela PUC-SP. E-mail: rosaccantal@gmail.com. ORCID iD 0000-0003-4716-4638
} 
https://doi.org/10.20873/uft.2359-0106.2021.v8n1.p231-252

\begin{abstract}
This scientific article aims to promote a reflection on the changes promoted by Constitutional Amendment No. 103/2019 in relation to the necessary requirements for the retirement of women in comparison with the retirement of men. It presents an analysis on the participation of men and women in the (paid) labor market, as well as the hours dedicated to social reproduction, which is not counted for retirement purposes, based on the demonstration of the interrelationships between their work activities and social. The present study examined studies that showed the difficulty faced by women to obtain the necessary time for retirement, since staying in employment, due to numerous factors, is much more complicated for her. In this way, it will be checked whether there have been significant changes in the labor market for women, as well as whether there is an equality of conditions between the sexes in order to justify these changes, since the requirements have become even more stringent for women and men. that this can negatively impact them.
\end{abstract}

Keywords: Woman retirement. Covid-19. Gender inequality. Job Market. Social reproduction.

\title{
1 CONSIDERAÇÕES INICIAIS
}

A aposentadoria surgiu no Brasil, para ambos os sexos, em 1923, mas foi somente a partir da publicação da Lei Orgânica de Previdência Social (Lei no 3.807/1960) que se passou a exigir cinco anos de contribuição a menos para as mulheres. Conforme se verá, isso se deu como forma de reconhecimento de trabalho relativo a atividades não remuneradas no ambiente familiar.

As condições diferenciadas para a aposentadoria da mulher somente foram inseridas no texto constitucional com a promulgação da Constituição Federal de 1967. Esses critérios se mantiveram com a Constituição Federal de 1988. Recentemente, a PEC no 287/2016, proposta no governo Temer, previu a igualdade de requisitos para a aposentadoria entre homens e mulheres; todavia, tal proposta foi interrompida em seus tramites no Congresso Nacional.

O assunto veio novamente a ser debatido através da Proposta de Emenda à Constituição no 6/2019, que culminou na Emenda Constitucional № 103/2019; dessa vez, promovendo importantes alterações, que reduzem as diferenças nos requisitos da 
aposentadoria entre homens e mulheres, mas que não igualam os requisitos de aposentadoria, nada obstante vindo a prejudicá-la, como se verá. Em suma, este artigo pretende comparar as aposentadorias do homem e da mulher antes e depois da EC no 103/2019, com relação às mudanças.

Quadro 01 - Mudanças na aposentadoria trazidas pela EC nำ103/2019

\begin{tabular}{|c|c|c|c|c|c|c|c|c|}
\hline & \multicolumn{4}{|c|}{ ANTES } & \multicolumn{4}{|c|}{$\begin{array}{c}\text { ATUAL } \\
\text { (EC № 103/2019) }\end{array}$} \\
\hline & \multicolumn{2}{|c|}{ IDADE } & \multicolumn{2}{|c|}{ TEMPO } & \multicolumn{2}{|c|}{ IDADE } & \multicolumn{2}{|c|}{ TEMPO } \\
\hline & $\mathbf{M}$ & H & $\mathbf{M}$ & H & $\mathbf{M}$ & H & $\mathbf{M}$ & $\mathbf{H}$ \\
\hline $\begin{array}{l}\text { Trabalhadores RGPS } \\
\text { ldade }\end{array}$ & 60 & 65 & 15 & 15 & 62 & 65 & 15 & 20 \\
\hline $\begin{array}{l}\text { Por tempo de contribuição } \\
\text { RGPS }\end{array}$ & N.A & N.A & 30 & 35 & 62 & 65 & 15 & 20 \\
\hline Servidores federais & 55 & 60 & 30 & 35 & 62 & 65 & 25 & 25 \\
\hline Professora/Servidora & 50 & 55 & 25 & 30 & 57 & 60 & 25 & 25 \\
\hline Prof. RGPS & N.A & N.A & 25 & 30 & 57 & 60 & 25 & 25 \\
\hline Policiais federais & N.A & N.A & 25 & 30 & 55 & 55 & 25 & 25 \\
\hline
\end{tabular}

Fonte: elaborado pelas autoras. Legendas: M - Mulher, H - Homem, N.A. - Não se aplica.

Conforme resumo da reforma no Quadro 01, é possível se verificar que as mudanças foram mais rígidas para as mulheres. A regra geral do RGPS passou a prever que a mulher se aposente aos 62 anos de idade e o homem aos 65, com tempo de contribuição de 15 anos para a mulher e 20 para o homem. Verifica-se que houve um aumento de dois anos no requisito idade da mulher, ao passo que, com relação ao homem, não houve qualquer alteração nesse requisito.

Com relação aos servidores federais, as alterações para as mulheres também foram maiores, pois houve aumento de sete anos na exigência da idade para a aposentadoria da mulher e, com relação ao homem, a alteração foi somente em cinco anos. Assim, dos 55 anos de idade para as mulheres se aposentarem, mudou para 62 anos e, para os homens, de 60 anos, mudou para 65 anos. Observa-se, ainda, que, no 
tempo de contribuição, houve uma diminuição de dez anos para o homem e somente cinco anos para a mulher, passando a ser de 25 anos para ambos.

As professoras também foram afetadas, pois a previsão é que elas se aposentem aos 57 anos. Com relação às professoras servidoras, na regra anterior, bastavam 50 anos e, para as filiadas no regime geral, não havia idade. Para o professor, o requisito idade alterou de 55 para 60 anos, ou seja, teve aumento de cinco anos e, para as professoras, o aumento foi de sete anos para aposentadoria. Verificase que o tempo de contribuição do professor, que antes era de 30 anos, caiu para 25.

E esses eventos vão se repetindo em outras categorias. Para os policiais da esfera federal que ingressarem na carreira após a aprovação da reforma, é necessário, para ambos os sexos, idade mínima de aposentadoria de 55 anos e o mínimo de 25 anos de contribuição. A norma anterior exigia apenas 25 anos de contribuição para as mulheres e 35 para os homens, não era necessário idade mínima.

Diante desse cenário de reformas, o presente trabalho analisará as modificações promovidas pela Emenda Constitucional no 103/2019, assim como, dos requisitos exigidos para a aposentadoria dos homens e das mulheres. Para isso, será fundamental compreender como a estrutura social interfere no trabalho remunerado, bem como as horas dedicadas à reprodução social, que não são contabilizadas para fins de aposentadoria, a partir da demonstração das inter-relações entre as suas atividades laborais e sociais.

Os estudos demonstram a dificuldade enfrentada pela mulher para conseguir o tempo necessário para aposentadoria, uma vez que manter-se no emprego, por inúmeros fatores, é muito mais complicado para ela.

Dessa forma, utilizando-se do método de análise bibliográfico quantitativo, verificar-se-á se houve mudanças significativas no mercado de trabalho da mulher, bem como se há uma igualdade de condições entre os sexos de modo a justificar essas alterações, uma vez que os requisitos ficaram ainda mais rigorosos para as mulheres.

\section{CENÁRIO ATUAL DO MERCADO DE TRABALHO DA MULHER}


Quando se faz uma comparação entre como era o mercado de trabalho para a mulher na década de 1960 e os momentos atuais, observa-se que, apesar de grandes avanços, ela continua tendo os mesmos obstáculos de antes. Portanto, não se justificam essas alterações tão rígidas nos critérios de sua aposentadoria. Conforme ratificado por Andreucci:

(...) quando da criação da norma diferenciadora dos critérios de concessão para aposentadoria por idade e por tempo de serviço (nomenclatura da época) favoravelmente às mulheres, o fundamento maior para tal direito foi a sobrecarga laboral o acúmulo de trabalho em razão da dupla jornada (sic) advinda dos afazeres profissionais e domésticos compreendendo-se, aqui, os cuidados com a família marido e filhos. (ANDREUCCI, 2010, p. 202)

Da análise da situação do mercado de trabalho, constata-se que as desigualdades de gênero são bastante acentuadas.

Gráfico 01 - Taxa de participação no mercado de trabalho, das pessoas de 16 anos ou mais, por sexo - Brasil, 1995 a 2014

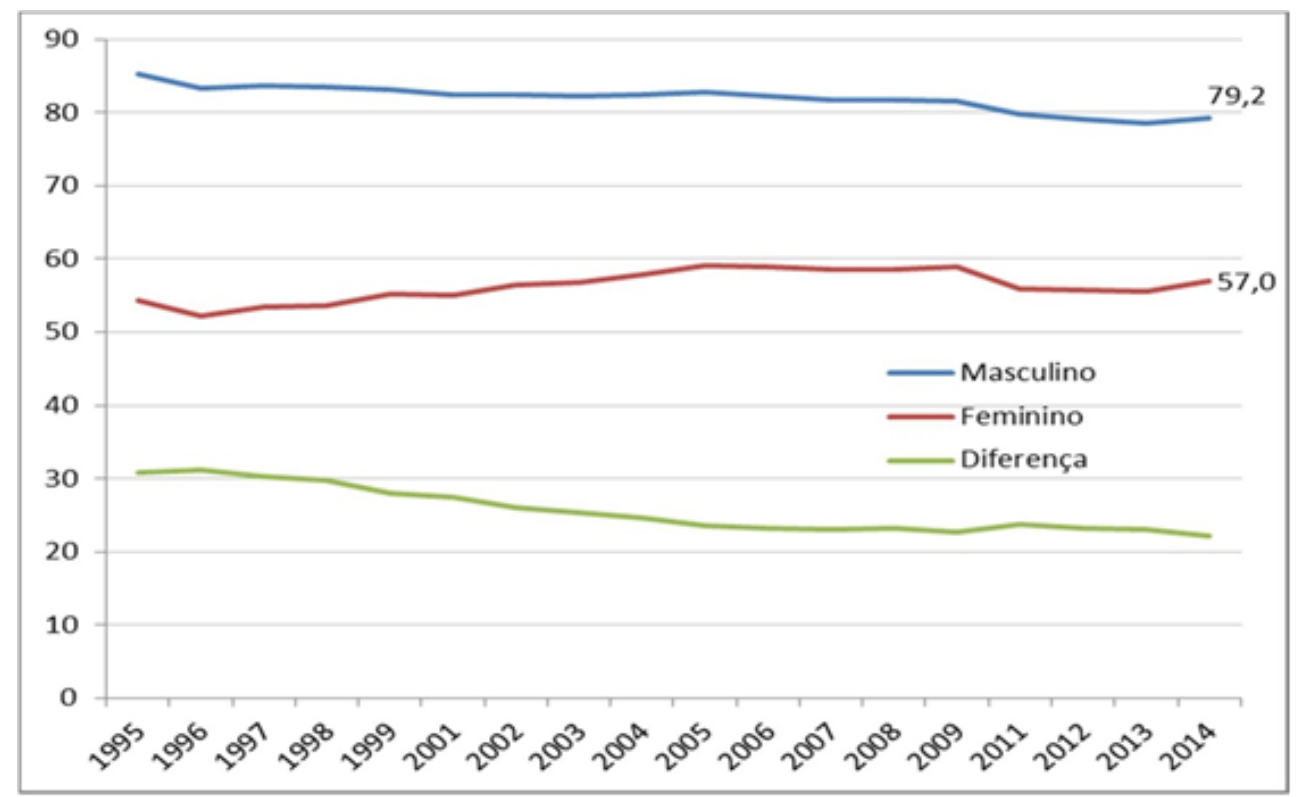

Fonte: IPEA, Nota Técnica 35. Dados do PNAD/IBGE. 
Conforme divulgação do PNAD/IBGE (2017, p.8) em uma pesquisa realizada entre 1995 e 2014 sobre a participação das pessoas de 16 anos ou mais no mercado de trabalho, vê-se que, em 2014 , a participação era de $79 \%$ para os homens e $57 \%$ para as mulheres.

$\mathrm{Na}$ verdade, esse período é apenas uma amostra, pois a participação dos homens no mercado de trabalho sempre foi maior do que a da mulher. Vários fatores indicam as dificuldades encontradas pelas mulheres para completar o tempo necessário de aposentadoria, fatores esses que intrincam a inserção no mercado de trabalho, bem como sua manutenção, impedindo que se complete o período necessário, situação que tende a se acentuar com a Emenda Constitucional oㅜ 103/2019.

A maternidade é um exemplo disso, uma vez que existem empregadores que, no momento da contratação, levam em conta a ausência da mulher com a licençamaternidade, bem como com os primeiros anos da infância de seus filhos, e deixam de efetuar a contratação. Esses elementos dificultam a comprovação do tempo de contribuição de maneira equânime. Por mais que se reconheça a inserção gradativa da mulher no mercado de trabalho, é fato que o papel dela, fruto de uma construção cultural, ainda está intimamente ligado a trabalhos relativos à reprodução social, envolvendo atividades domésticas e cuidados com membros da família.

Pesquisa realizada em 2018, pelo IBGE (2019), apontou que o tempo dedicado pelas mulheres aos afazeres domésticos e ao cuidado de pessoas próximas foi muito maior do que aquele praticado pelos homens: enquanto elas, não inseridas no mercado de trabalho, dedicavam 23,8 horas semanais a esse tipo de atividade, eles, na mesma situação, despendiam 12 horas. Quando enquadrados no mercado formal, o índice demonstrou que os homens dedicavam 10,30 horas a afazeres domésticos e o cuidado de pessoas, enquanto as mulheres na mesma situação dedicavam 18,5 horas. Evidenciam-se, nesses números, a grande desigualdade e o desafio constante para 0 sexo feminino, conciliar as exigências familiar e profissional, pois a situação de dupla jornada de trabalho, além de implicar num trabalho invisível e não remunerado, faz com 
que essas mulheres acabem tendo menos tempo disponível para 0 trabalho remunerado.

Segundo relatório divulgado pela Organização das Nações Unidas - Mulheres (ONU Mulheres) em 2016:

(...) as mulheres continuam ocupando os empregos com menores remunerações e baixa qualidade, além de viverem em condições mais precárias de saúde, de acesso à água e saneamento. O relatório informa também que as mulheres continuam sendo predominantemente responsáveis pelo cuidado com os filhos e com os idosos. (ONU MULHERES, 2015, p. 16)

Conforme estudo do Gráfico 02 a seguir, há uma tendência de aumento do nível de dependência dos idosos. Assim, embora conste uma queda na dependência dos filhos, a mulher continuará tendo o compromisso de cuidados com pessoas da família, pois, predominantemente, é ela quem desempenha essa função.

Gráfico 02 - Estimativa IBGE das razões de dependência de idosos (65 ou mais), crianças (0 a 14 anos) e total, em relação à população de 15 a 64 anos - Brasil (\%)

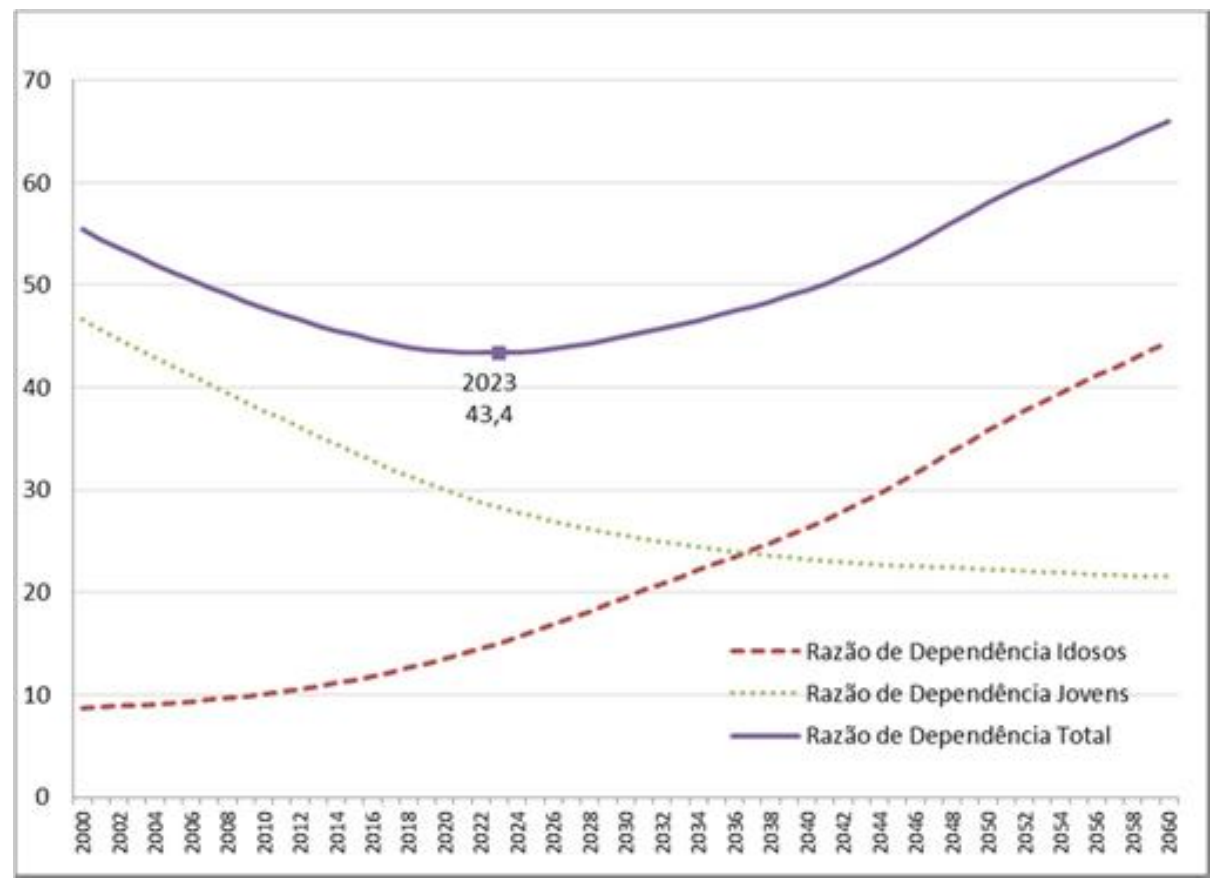


ISSN n 2359-0106

Vol. 8, n. 1, 2021.

https://doi.org/10.20873/uft.2359-0106.2021.v8n1.p231-252

Fonte: IPEA, Nota Técnica 35. Dados do PNAD/IBGE.

Vale ressaltar que é devido a essas características peculiares da mulher que há uma predominância delas em profissões ligadas ao cuidado e afazeres domésticos:

Os trabalhos remunerados carregam, inclusive, características dos trabalhos de cuidados e doméstico, como é o caso das ocupações nos campos da pedagogia, enfermagem, psicologia, assistência social, limpeza, beleza, preparação de alimentos e atendimento ao público, majoritariamente ocupados por mulheres e, via de regra, mais desvalorizados [grifo nosso]. (ONU MULHERES, 2015, p. 5)

Ainda é uma realidade no mundo do trabalho a Divisão Sexual do Trabalho estabelecendo em nossa sociedade quais são as atividades ditas femininas e masculinas. Às mulheres são destinadas trabalhos cujas qualidades são ditas naturais, sendo na verdade, construção cultural.

Para Kergoat a divisão sexual do trabalho é:

(...) a forma de divisão do trabalho social decorrente das relações sociais de sexo; essa forma é historicamente adaptada a cada sociedade. Tem por características a destinação prioritária dos homens à esfera produtiva e das mulheres à esfera reprodutiva e, simultaneamente, a ocupação pelos homens das funções de forte valor social agregado (políticas, religiosas, militares etc.) Essa forma de divisão social do trabalho tem dois princípios organizadores: o da separação (existem trabalhos de homens e outro de mulheres) e o da hierarquização (um trabalho de homem "vale" mais do que um de mulher). (KERGOAT, 2009, p. 67)

A visão androcêntrica da divisão sexual do trabalho "legitima uma relação de dominação inscrevendo-a em uma natureza biológica que é, por sua vez, ela própria uma construção social naturalizada". (BOURDIEU, 2011, p. 33)

As mulheres estão inseridas, em grande parte, em atividades precárias e vulneráveis, estão trabalhando na informalidade, são maioria no serviço terceirizado e possuem dupla ou tripla jornada de trabalho, ou seja, vivem na invisibilidade. 


\section{A SITUAÇÃO DA MULHER FRENTE AO COVID-19 E A PREVIDÊNCIA SOCIAL}

A pandemia do covid-19 tem escancarado a triste realidade das mulheres, principalmente com a adoção do teletrabalho. Sem o suporte da escola ou da rede de apoio, com a necessidade de cuidar dos filhos e organizar as atividades do lar, que ainda, fica predominantemente a cargo das mulheres, as trabalhadoras acabam sobrecarregadas, afetando a sua saúde metal e prejudicando a sua vida profissional, reforçando, assim, o machismo estrutural presentes na vida privada e no espaço público. Para Débora Diniz, professora da Universidade de Brasília - UNB, em entrevista alerta que na América Latina e Caribe:

(...) $59 \%$ dos trabalhadores informais são mulheres; $93 \%$ dos trabalhadores domésticos são mulheres; e $80 \%$ delas atuam na informalidade. Mesmo entre trabalhadoras domésticas com empregos formais, apenas $25 \%$ estão inseridas em sistemas de seguridade social. $(\mathrm{G} 1,2020)$

O que a pandemia tem demonstrado é que o teletrabalho ou home office tem sobrecarregado e estressado muito mais as mulheres que acabam aumentando as horas realizando tarefas domésticas, "para os homens, a única mudança de padrão foi sair mais para fazer compras". (EL PAIS BRASIL, 2020)

Durante a pandemia do covid-19, a ONU MULHERES, em março de 2020, detectou que as pessoas que estão trabalhando na linha de frente no setor social e de saúde, no mundo, $70 \%$ são mulheres. Sendo, justamente, as mulheres as que são mais vulneráveis no emprego, estando em maior número no desemprego. (ONU MULHERES, 2020) Consequentemente, são as mulheres as mais afetadas para completarem o tempo de contribuição da aposentadoria na pandemia, e portanto, para se aposentarem.

Outro dado que merece destaque é que a pandemia de Covid-19, justamente pelo fato das mulheres ficarem mais tempo em casa isoladas com seus maridos, 
causou um aumento da violência doméstica, que se não impossibilita a continuidade da vida dessas mulheres, prejudica sua qualidade de vida e consequentemente de rendimento de trabalhos home office, acarretando, prejuízos para aposentadoria.

De acordo com um relatório produzido pelo Fórum Brasileiro de Segurança Pública (FBSP), intitulado "Violência Doméstica durante a Pandemia de Covid-19", entre março e abril deste ano, em 12 estados do país, comparativamente ao ano passado, os casos de feminicídio cresceram $22,2 \%$, tendo como referência dados coletados nos órgãos de segurança dos estados brasileiros. (AGÊNCIA BRASIL, 2020)

A Organização Pan-Americana da Saúde (Opas), alertou em dezoito de agosto de 2020, que a pandemia do coronavírus gerou, entre outras mazelas, "depressão, ansiedade e estresse". Em suas palavras: "Uma 'crise de saúde mental' sem precedentes em todo o continente americano". (FOLHA DE PERNAMBUCO, 2020)

\section{ARGUMENTOS QUE EMBASAM A APOSENTADORIA ANTECIPADA DA MULHER}

De fato, houve maior inclusão da mulher no mercado de trabalho. Todavia, as desigualdades persistem de forma acentuada e as oportunidades continuam sendo maiores para os homens, o que fica mais claro quando se leva em conta que, somadas as horas de trabalho remunerado com os afazeres domésticos, a mulher trabalha um tempo muito maior.

No tocante à dupla jornada, importante reportar-se ao estudo realizado por Correa et al, "A questão previdenciária: simulações quanto à igualdade de gênero. Vantagem para previdência social e desvantagem para a mulher" (FÉLIX, MYRRHA, CORRÊA, 2016, p.14) que demonstra a quantidade de horas despendidas nos trabalhos remunerados e afazeres domésticos, por homens e mulheres, ficando evidenciada a jornada ampliada delas, pois os homens dedicam 11 horas e a mulher 24 horas a afazeres domésticos. 
Tabela 01 - Percentual de homens e de mulheres com trabalho remunerado e que se dedicaram a afazeres domésticos na semana de referência, e média de horas semanais em cada atividade, Brasil, 2014

\begin{tabular}{|l|c|c|}
\hline \multicolumn{1}{|c|}{ Atividade } & Homens & Mulheres \\
\hline Trabalhando na semana de referência & $65 \%$ & $44 \%$ \\
\hline Cuidavam dos afazeres domésticos & $51 \%$ & $88 \%$ \\
\hline Média de horas de trabalho remunerado & 41 & 35 \\
\hline Horas em afazeres domésticos semanais & 11 & 24 \\
\hline Total & 52 & 59 \\
\hline Rendimento médio mensal (R\$) & $1.896,00$ & $1.431,00$ \\
\hline Rendimento médio por hora (R\$) & 11,56 & 10,22 \\
\hline $\begin{array}{l}\text { Média de horas semanais no trabalho remunerado na } \\
\text { igualdade de gênero }\end{array}$ & 41,00 & 39,59 \\
\hline
\end{tabular}

Fonte: Microdados PNAD 2014, IBGE.

É inegável que uma ampla parte das mulheres dedica grande parcela do seu tempo a afazeres domésticos no Brasil, expondo uma enorme desigualdade de oportunidade e qualidade de emprego entre ambos. Nesse mesmo artigo é feito um cálculo matemático no qual se apurou quanto um homem e uma mulher acumulam de horas de trabalho, observando os períodos: semana, ano, trinta e trinta e cinco anos.

Tabela 02 - Média de horas trabalhadas em uma semana, em um ano e em 35 e 30 anos, para homens e mulheres, respectivamente, considerando trabalho remunerado e afazeres domésticos, Brasil, 2014

\begin{tabular}{|c|c|c|c|c|c|c|c|c|}
\hline \multirow{2}{*}{$\begin{array}{c}\text { TIPO DE } \\
\text { TRABALHO }\end{array}$} & \multicolumn{4}{|c|}{ HOMENS } & \multicolumn{4}{c|}{ MULHERES } \\
\cline { 2 - 10 } & Semana & Ano & 30 anos & 35 anos & Semana & Ano & 30 anos & 35 anos \\
\hline Remunerado & 41 & 1.968 & 59.040 & 68.880 & $39,59^{*}$ & 1.900 & 57.000 & 66.500 \\
\hline Doméstico & 11 & 528 & 15.840 & 18.480 & 24 & 1.152 & 34.560 & 40.320 \\
\hline Total & 52 & 2.496 & 74.880 & 87.360 & 64 & 3.052 & 91.555 & 106.814 \\
\hline
\end{tabular}

Fonte: Microdados PNAD 2014, IBGE.

Como resultado do estudo de Correa et al, (FÉLIX, MYRRHA, CORRÊA, 2016, p.15) constata-se que as mulheres, ao longo de sua vida laboral, considerando horas 
de trabalho remunerado e afazeres domésticos, trabalham em média $22,3 \%$ a mais do que os homens, o que justificaria sua aposentadoria antecipada.

Dado que as mulheres trabalham, em média, 91.555 horas em 30 anos, e os homens trabalham 87.360 horas em 35 anos, em 30 anos as mulheres têm mais horas trabalhadas que os homens em 35 anos. Ou seja, o bônus previdenciário de 5 anos concedido para as mulheres ainda é insuficiente para compensar a dupla jornada feminina e os diferenciais salariais no mercado de trabalho experimentados ainda hoje. Se a mulher trabalha, em média, $22,3 \%$ mais que os homens, para cada ano de trabalho da mulher deveria corresponder a 1,22 anos de trabalho dos homens. Se os homens se aposentam após 35 anos de trabalho, a mulher poderia se aposentar após 28,7 ou 29 anos de trabalho. (FÉLIX, MYRRHA, CORRÊA, 2016, p.16)

Depreende-se, por meio desse estudo, que as horas trabalhadas e não remuneradas pelas mulheres corresponderiam aproximadamente a 6 anos a menos de trabalho, para fins de idade e tempo de contribuição para as mulheres. Conforme aponta a Organização Ibero-americana de Seguridade Social (OISS), em 2014, (OISS, 2014, p. 05) a mulher desempenha trabalhos mais precários do que o homem, com maior incidência de contratos por prazos determinados e maior interrupção na carreira, segundo o Programa sobre equidad de género en los sistemas de Seguridad Social.

(...) as desigualdades de gênero no trabalho se mantêm. Entre os fatos relatados, destacam-se: os principais setores de emprego para as mulheres na América Latina são o serviço doméstico, fabricação de tecidos e agricultura sazonal: no trabalho realizado pela mulher, há maior incidência de contratos a prazo determinado e há interrupção maior na carreira, devido ao cuidado com familiares (filhos e idosos); as mulheres são as primeiras a perderem seus empregos. (OISS, 2014, p. 43)

Corroborando as informações apresentadas, estimativa do IBGE (2018) referente ao ano de 2018 indica que o salário médio pago às mulheres foi apenas $77,2 \%$ do rendimento pago aos homens no Brasil: enquanto o homem recebia, em média $R \$$ $2.416,00$, a mulher recebia $R \$ 1.875,00$, evidenciando, mais uma vez, uma gritante 
disparidade. Apesar de a Tabela 03 fazer referência apenas ao ano 2018, é evidente que essa diferença sempre existiu.

Importante destacar que quando se fala em mulheres negras no mercado de trabalho, o cenário é ainda mais díspare, se comparado ao recebido pelas mulheres brancas: segundo o levantamento do Departamento Intersindical de Estatísticas e Estudos Econômicos (DIEESE,2019), as mulheres negras possuem renda média 70,5\% inferior à das mulheres brancas.

Imagem 1 - Tabela 5429 Rendimento médio nominal, habitualmente recebido por mês e efetivamente recebido no mês de referência, do trabalho principal e de todos os trabalhos, por sexo.

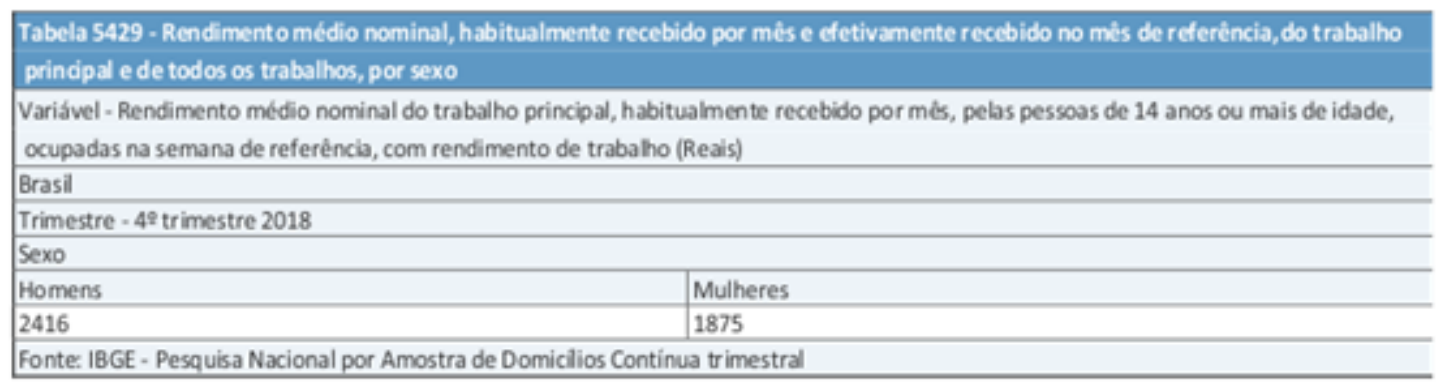

Fonte: IBGE/PNUD

Segundo anuário do INSS, (SECRETARIA DA PRESIDÊNCIA, 2017, p. 20) em 2017, a mulher, ao final de sua vida laboral, conseguia somar 22 anos de contribuição, enquanto os homens completavam os 35 , razão pela qual as aposentadorias por idade aos 60 anos eram as mais concedidas para elas. Atualmente, com a exigência de 30 anos de contribuição, a missão tornou-se ainda mais inconcebível, tanto que, em 2017, $62,8 \%$ do total de aposentadorias por idade concedidas no RGPS eram com relação às mulheres, contra apenas $37,2 \%$ de homens. Em contrapartida, nas aposentadorias por tempo de contribuição, as dos homens correspondiam a $68,1 \%$ e as mulheres a $31,9 \%$. Em face desses números, depreende-se que, se já havia essa discrepância, as novas regras trarão consequências ainda mais assoladoras.

Salienta-se que, na época, a justificativa levantada para a diminuição do tempo necessário para a aposentadoria foi a dupla jornada. Não se discutiu a expectativa de 
vida da mulher. E isso vai conforme a informação de Mostafa et al de que este não é fator decisivo da diferenciação das idades para acesso à aposentadoria:

A rigor, a diferenciação das idades de acesso à aposentadoria não tem qualquer relação com expectativa de vida: a distinção de critérios guarda proporcionalidade com as condições desiguais de inserção de homens e mulheres no mundo do trabalho. (MOSTAFA, 2017, p. 07)

Os motivos apresentados para que houvesse a Reforma da Previdência foram: maior expectativa de vida, queda da natalidade, novos arranjos familiares, melhor inserção da mulher no mercado de trabalho, dentre outros. Contudo, nossa pesquisa demonstra que o fator predominante da diferenciação da aposentadoria entre o homem e mulher é a dupla jornada de trabalho, que leva em conta fatores que implicam na justiça e equidade entre homens e mulheres, considerando os aspectos culturais e sociais.

Considerando todos os motivos elencados, tem-se que a diferenciação do tempo de aposentadoria da mulher em relação à aposentadoria do homem trata-se em verdade de uma questão de justiça social, que se realiza também através da concretização do princípio da igualdade. Importante destacar que a Constituição Federal, em seu art. 5으., inciso I, estabelece que homens e mulheres são iguais em direitos e obrigações. Tal afirmação evoca o Princípio da Igualdade. Entretanto, é preciso ressaltar que esse princípio deve ser analisado em duas dimensões, quais sejam, a igualdade formal e a igualdade material.

A igualdade formal é a igualdade ideal, "aquela estabelecida como ideal, perante a lei, que deve garantir um tratamento igualitário de homens e mulheres e a todos perante o ordenamento legal, sem privilégios e distinções". (ANDREUCCI, 2010, p. 115) Podem ser elencados como exemplos da igualdade formal, norma que proíbe a diferença de salários, no exercício de funções iguais e de adoção de critério de admissão por motivo de sexo, que estão estabelecidos no artigo $7^{\circ}, X^{\circ} X X$, da Constituição Federal, entre outros. 
No que se refere à igualdade material, esta equivale à igualdade real, que reconhece a diversidade entre os seres humanos, buscando realizar a igualdade no plano fático e visando a reduzir as desigualdades sociais. Com relação ao assunto abordado neste artigo, tem como exemplo de igualdade material as diferenças dos requisitos exigidos para a aposentadoria entre homens e mulheres, qual seja, tempo de contribuição de 30 anos para mulheres e 35 para os homens e 60 anos de idade para as mulheres e 65 para os homens. $O$ tratamento diferencial no que diz respeito à idade de aposentadoria entre homens e mulheres é reconhecido pela Constituição Federal, art. 201, parágrafo 7º e artigo 40, parágrafo 1ํㅡ. III, a e $b$.

Segundo Pierdoná, (PIERDONÁ, 2019) que defende que não deve haver diferenças de requisitos com relação à aposentadoria do homem e da mulher, não se justifica a manutenção das atuais diferenças de idade e tempo de contribuição entre eles para a aposentadoria, sob a alegação de que, a Constituição Federal, em seu art. $5^{\circ}$, I, estabelece que homens e mulheres são iguais em direito e obrigações.

Com relação a essa afirmação, importante destacar que o princípio da igualdade permite, e muitas vezes exige, tratamentos diferenciados, e isso é melhor demonstrado por Kelsen:

A igualdade dos sujeitos na ordenação jurídica, garantida pela Constituição, não significa que estes devam ser tratados de maneira idêntica nas normas (e, em particular, nas leis expedidas com base na Constituição). A igualdade assim entendida não é concebível: seria absurdo impor a todos os indivíduos exatamente as mesmas obrigações ou lhes conferir exatamente os mesmos direitos, sem fazer distinção alguma entre eles, como, por exemplo, entre crianças e adultos, indivíduos mentalmente sadios e alienados, homens e mulheres. (KELSEN Apud MELLO, 2006, p. 190)

Celso Antônio Bandeira de Mello ( 2006, p. 15-17) chama atenção para o fato de imaginar-se que certos fatores diferenciais existentes nas pessoas não poderiam ser adotados pela norma como base para alguma diferenciação. No entanto, "(...) qualquer elemento existente nas coisas, pessoas ou situações pode ser escolhido pela lei como 
fator discriminatório (...)", desde que vise a assegurar a igualdade real entre os sujeitos. Por exemplo: admissão apenas de mulheres em concursos para cargo de "Polícia feminina", o que requer características que só podem ser atribuídas às mulheres, como é o caso da revista íntima; Lei Maria da Penha (no 11.340/2006), que reconhece a vulnerabilidade da mulher em situação de violência doméstica; e na Lei no 9504/97, que estabelece um percentual de vagas para candidatas mulheres e garante a participação das mulheres nos processos eleitorais, conferindo-lhe especial proteção e lei. Assim sendo, as mulheres devem ser respeitadas pelas suas peculiaridades e serem tratadas de forma diferenciada tanto pela sua estrutura biológica como pelas diferenças socioculturais e socioeconômicas.

É importante destacar que, por outro lado, segundo o professor Luiz David Araújo, a máxima aristotélica segundo a qual deve haver tratamento igual aos iguais e desigual aos desiguais, na medida dessa desigualdade, apesar de correta, requer maior explicação a fim de determinar-se o sentido e o alcance do princípio da isonomia, no caso concreto, uma vez que a grande dificuldade reside exatamente em determinar, em cada caso, quem são os iguais, quem são os desiguais e qual a medida dessa desigualdade.

Dessa forma, na situação em comento, será necessário identificar os critérios diferenciadores do referido princípio e determinar os fatores que permitem estabelecer uma correlação lógica entre o fator discriminatório e o fundamento jurídico distinto, diferenciado, entre homens e mulheres, no tocante ao tempo de contribuição e idade, para fins de aposentadoria, à luz dos valores protegidos pela Constituição Federal.

De acordo com o prof. Luiz Alberto David Araujo, (2018, p. 205-206) para estabelecer esses critérios diferenciadores, seria necessário determinar três fatores, que passamos a apresentar para explicar o significado no caso concreto: 1) Fator adotado como critério discriminatório; 2) Correlação lógica entre o fator discriminatório e o tratamento jurídico atribuído em face da desigualdade apontada; 3) Afinidade entre a correlação apontada no item anterior e os valores protegidos pelo nosso ordenamento constitucional. 
Conforme demonstrado, as mulheres apresentam diferenças biológicas, socioeconômicas e socioculturais em relação ao homem, que acarretam uma desigualdade de gênero; têm maior dificuldade de se inserir e se manter no mercado de trabalho; por outro lado, realizam uma sobrejornada de trabalho. Portanto, este deve ser o critério discriminatório a ser adotado.

Por conseguinte, em razão da desigualdade de gênero concreta suportada pela mulher, o princípio da igualdade material deve ser um valor de predominância na escolha do legislador entre o fator discriminatório e o tratamento jurídico atribuído em face da desigualdade apontada. Consequentemente, em virtude de todas as razões, conclui-se que é justo prevalecer critérios diferenciados para aposentadoria da mulher, como forma de concretização do princípio da igualdade em sua dimensão material, visto que, no momento, não se tem uma igualdade formal e, principalmente, por uma questão de justiça social.

\section{CONSIDERAÇÕES FINAIS}

De acordo com o estudo apresentado, infere-se que ainda é a mulher que predominantemente desempenha as atividades de reprodução social. Em decorrência disso, se somarmos as horas de trabalho dela em relação aos homens, verifica-se que trabalha bem mais.

Sempre houve desigualdades no mercado de trabalho, que geravam grande dificuldade para a mulher alcançar o tempo de contribuição necessário para a aposentadoria e as alterações advindas com a Emenda Constitucional № 103/2019 inviabilizarão ainda mais essa aposentadoria. Depreendeu-se também que, ainda hoje, temos uma sociedade patriarcal quando se trata das condições de trabalho da mulher, que não mudou o suficiente em relação ao momento em que foi instituída essa diferenciação de tempo e idade na aposentadoria. Mais do que isso: o cenário atual em muito pouco se distingue daquele em que a lei criou os critérios diferenciadores da aposentadoria da mulher em relação ao homem, sendo predominante a dupla jornada de trabalho. 
Os motivos apresentados para que houvesse a Reforma da Previdência foram: maior expectativa de vida, queda da natalidade, novos arranjos familiares, melhor inserção da mulher no mercado de trabalho, dentre outros, fatores que, conforme demonstrou nossa pesquisa, não alteram substancialmente a realidade da mulher no mercado de trabalho formal e no trabalho não remunerado e invisibilizado, considerando aspectos cultuais e sociais da mulher no Brasil.

Ademais, deve-se aplicar o princípio constitucional da igualdade material, que diz tratar os iguais de forma igual e os desiguais de forma desigual, de forma à concretização da justiça social, reconhecendo-se, portanto, essas diferenças na legislação previdenciária. O não reconhecimento desse fato implica em consequências que vão aumentar ainda mais a desigualdade existente e trazer abalo à estrutura familiar.

Se considerar, através das pesquisas, o tempo de trabalho da mulher ao longo de sua vida laboral, verifica-se que ela faria jus a uma aposentadoria ainda mais antecipada do que já é. No entanto, não foi considerado isso na ocasião da Reforma Previdenciária e quiçá de sua previsão na legislação constitucional, com o advento das Constituições de 1967 e 1988.

As mulheres, predominantemente, desempenham atividades ligadas à reprodução social e a trabalhos precários. Manter-se no mercado de trabalho até atingir os requisitos para a aposentadoria é um grande desafio para as mulheres, o que justifica a manutenção e até redução da idade diferida a menor. Esses requisitos impossibilitam que elas completem o período exigido, podendo inclusive levá-las a um aumento de afastamentos por incapacidade.

Verificou-se, ainda, que, ao longo de sua vida laboral, a mulher, devido à dupla jornada, trabalha mais do que o homem, tornando indispensável essa maior distinção entre suas aposentadorias. Apesar da atual reforma trazer uma diferença tanto de idade quanto de contribuição, esses requisitos não parelham homem e mulher para que ambos cheguem ao fim da vida profissional em pé de igualdade.

Em virtude de todas as razões apontadas, conclui-se que, ainda que com a Reforma da Previdência, o peso maior recaiu sobre as mulheres, uma vez que, em 
longo prazo, terão mais dificuldades para cumprir os pré-requisitos imprescindíveis para aquisição de um mínimo de segurança no fim de sua vida profissional.

\section{REFERÊNCIAS}

AGÊNCIA BRASIL. Casos de feminicídio crescem 22\% em 12 estados durante pandemia. Disponível em: https://agenciabrasil.ebc.com.br/direitoshumanos/noticia/2020-06/casos-de-feminicidio-crescem-22-em-12-estados-durantepandemia. Acesso em: 24 ago. 2020.

ANDRADE, Tânia. Mulheres no Mercado de Trabalho Onde Nasce a Desigualdade? Consultora Legislativa da Área v. Direito do Trabalho e Processual do Trabalho. Estudo Técnico, jul. 2016. Disponível em: https://www2.camara.leg.br/atividadelegislativa/estudos-e-notas-tecnicas/publicacoes-da-consultoria-legislativa/areas-daconle/tema7/2016 12416 mulheres-no-mercado-de-trabalho tania-andrade. Acesso em: 21 abr. 2019.

ANDREUCCI, Ana Cláudia Pompeu Torezan. Igualdade de gênero e ações afirmativas: desafios e perspectivas para as mulheres brasileiras pós-constituição federal de 1988. São Paulo: LTr, 2012.

Por uma efetiva construção da igualdade de gênero no ordenamento jurídico brasileiro: análise da necessária revisão do tratamento diferenciado à mulher nas aposentadorias por idade e por tempo de contribuição na Constituição Federal de 1988. 2010. 298 f. Tese (Doutorado em Direito) - Pontifícia Universidade Católica de São Paulo, São Paulo, 2010.

ARAÚJO, Luiz Alberto David; JÚNIOR, Vidal Serrano Núnes. Curso de Direito Constitucional. 22ª edição. São Paulo: Verbatim, 2018.

BOURDIEU, Pierre. A dominação masculina. Rio de Janeiro: Bertrand Brasil, 2011.

CAMARANO, Ana Amélia. $\mathbf{O}$ envelhecimento populacional na agenda das políticas públicas, $\quad$ p. 253-292. Disponível em: http://www.ipea.gov.br/portal/images/stories/PDFs/livros/Arq 16 Cap 08.pdf. Acesso em: 25 abr. 2019.

CAMARGO, Elaine Cristina Beltran de. O direito, a mulher e o mercado de trabalho. In: PINTO, Roberto Parahyba de Arruda; CAMARANO, Alessandra; HAZAN, Ellen Mara Ferraz (Coords.). Feminismo, pluralismo e democracia. São Paulo: Ltr, 2018. 
CARTAXO, Ana Maria Baima. A reforma da política previdenciária brasileira na década de 90: um estudo de suas determinações sócio-históricas. 2003. 358 f. Tese (Doutorado em Serviço Social) - Pontifícia Universidade Católica de São Paulo, São Paulo, 2003.

DIEESI. PEC 06/2019: As Mulheres Outra Vez Na Mira Da Reforma Da Previdência. Nota Técnica 202/2019. Disponível em: https://www.dieese.org.br/notatecnica/2019/notaTec202MulherPrevidencia.pdf. Acesso em: 23 set. 2020.

EL PAIS BRASIL. "Trabalho de madrugada porque não dou conta de tudo em casa", a nova normalidade massacra as mulheres. 28/05/2020 Disponível em: https://brasil.elpais.com/smoda/2020-05-28/trabalho-de-madrugada-porque-nao-douconta-de-tudo-em-casa-a-nova-normalidade-massacra-as-mulheres.html. Acesso em: 22 out. 2020.

FÉLIX, Fernanda Fonseca; MYRRHA, Luana Junqueira Dias; CORRÊA, Cristiane Silva. A questão previdenciária: simulações quanto à igualdade de gênero. Vantagem para previdência social e desvantagem para a mulher. Disponível em: http://www.abep.org.br/xxencontro/files/paper/728-455.pdf. Acesso em: 24 abr. 2020.

Folha de Pernambuco. Pandemia causou 'crise de saúde mental' inédita e 'aumento da violência doméstica', diz Opas. Disponível em: https://www.folhape.com.br/noticias/pandemia-causou-crise-de-saude-mental-inedita-eaumento-da/151319/. Acesso em: 24 ago. 2020

FONSECA, Marcia Gabriela Tramontini. Uma análise crítica frente à paridade na adoção da idade para aposentadoria na reforma previdenciária para homens e mulheres. Caxias do Sul, RS: Plenum, 2019.

G1. Como a pandemia de coronavírus impacta de maneira mais severa a vida das mulheres em todo o mundo. 19/04/2020. Disponível em: https://g1.globo.com/bemestar/coronavirus/noticia/2020/04/19/como-a-pandemia-decoronavirus-impacta-de-maneira-mais-severa-a-vida-das-mulheres-em-todo-omundo.ghtml. Acesso em: 11 jul. 2020.

HORVATH JÚNIOR, Miguel. Direito Previdenciário. 11ª edição. São Paulo: Quartier, 2017.

IBGE. Mulheres dedicam mais horas aos afazeres domésticos e cuidados de pessoas, mesmo em situações ocupacionais iguais às dos homens. Publicada em: 26/04/2019. Disponível em: https://agenciadenoticias.ibge.gov.br/agencia-sala-deimprensa/2013-agencia-de-noticias/releases/24266-mulheres-dedicam-mais-horas-aos- 
afazeres-domesticos-e-cuidado-de-pessoas-mesmo-em-situacoes-ocupacionais-iguaisa-dos-homens. Acesso em: 22 abr. 2019.

INSTITUTO DE PESQUISA ECONÔMICA APLICADA (IPEA). Nota Técnica no35 Previdência e gênero: por que as idades de aposentadoria de homens e mulheres devem ser diferentes? Brasília: 2017. Disponível em: https://www.ipea.gov.br/portal/images/stories/PDFs/nota tecnica/20170321 nt35-discoprevidencia-e-genero.pdf. Acesso 22 abr. 2020.

KERGOAT, Daniéle. Divisão Sexual do Trabalho e relações sociais de sexo. In: HIRATA, Helena; LABORIE, Françoise; LE DOARÉ, Héléne; SENOTIER, Daniéle (Orgs.) Dicionário Crítico do Feminismo. São Paulo: Editora UNESP, 2009.

LADENTHIN, Adriane Bramante de Castro; BERWANGER, Jane Lucia Wilhelm; ECKERT, Julieth Berwanger. A Previdência social como instrumento para efetivação da igualdade de gênero. In: PINTO, Roberto Parahyba de Arruda; CAMARANO, Alessandra; HAZAN, Ellen Mara Ferraz (Coords.). Feminismo, pluralismo e democracia. São Paulo: Ltr, 2018.

LAVINAS, Lena. Faz sentido haver idades diferentes para aposentadorias de homens e mulheres? Sim. Publicado em: 23/02/2019. Disponível em: https://www1.folha.uol.com.br/opiniao/2019/02/faz-sentido-haver-idades-diferentespara-aposentadorias-de-homens-e-mulheres-sim.shtml. Acesso em: 24 abr. 2019.

LEITE, Jorge Salomão; SARLET, Ingo Wolfsgang (Coords.). Direitos fundamentais e estado constitucional: estudos em homenagem a J. J Gomes Canotilho. São Paulo: Revista dos Tribunais, Coimbra, Portugal: Coimbra Editora, 2009.

MELLO, Celso Antonio Bandeira. Conteúdo jurídico do Princípio da Igualdade. $3^{a}$ ed. São Paulo: Malheiros, 2006.

MELO, Hildete. A questão de gênero no Projeto da Reforma da Previdência Social: uma visão histórica. Disponível em: http://www.periodicos.ufpb.br/ojs/index.php/abet/article/view/36027. Acesso em: 23 abr. 2019.

MOSTAFA, J. et al. Nota Técnica no 35 - IPEA: Previdência e gênero por que as idades de aposentadoria de homens e mulheres devem ser diferentes? Mar. de 2017. Disponível em: http://www.ipea.gov.br/portal/index.php?option=com content\&view=article\&id=29641:no ta-tecnica-2017-marco-numero-35-disoc-previdencia-e-genero-por-que-as-idades-deaposentadoria-de-homens-e-mulheres-devem-serdiferentes\&catid=192:disoc\&directory=1. Acesso em: 23 abr. 2019. 
ONU MULHERES. COVID-19: Mulheres à frente e no centro. 27/03/2020. Disponível em: $\quad$ http://www.onumulheres.org.br/noticias/covid-19-mulheres-a-frente-e-no-centro/. Acesso em: 10 jul. 2020.

. Progresso das mulheres no mundo 2015-2016 - Transformar as economias para realizar direitos. Nova York (EUA): 2015. Disponível em: https://www.unwomen.org//media/headquarters/attachments/sections/library/publications/2015/poww-2015-2016pt.pdf?la=es\&vs=3629. Acesso em: 22 abr. 2020.

PIERDONÁ, Zélia Luiza. Faz sentido haver idades diferentes para aposentadorias de homens e mulheres? Não. Publicado em: 23/02/2019. Disponível em: https://www1.folha.uol.com.br/opiniao/2019/02/faz-sentido-haver-idades-diferentespara-aposentadorias-de-homens-e-mulheres-nao.shtml. Acesso em: 24 abr. 2019.

PINTO, Roberto Parahyba de Arruda; CAMARANO, Alessandra; HAZAN, Ellen Mara Ferraz (Coords.). Feminismo, pluralismo e democracia. São Paulo: Ltr, 2018.

RIEDEL, Thais. A mulher na Previdência e o princípio da vedação do retrocesso, págs 341-349. In: PINTO, Roberto Parahyba de Arruda; CAMARANO, Alessandra; HAZAN, Ellen Mara Ferraz (Coords.). Feminismo, pluralismo e democracia. São Paulo: Ltr, 2018. 